\title{
Hypoglycemic property of triterpenoid saponin PFS isolated from Polyscias fruticosa leaves
}

\author{
NGUYEN THI LUYEN ${ }^{1}$, NGUYEN HAI DANG ${ }^{2}$, PHUNG THI XUAN \\ BINH $^{3}$, NGUYEN THI HAI ${ }^{4}$ and NGUYEN TIEN DAT ${ }^{1}$ \\ ${ }^{1}$ Center for Research and Technology Transfer, Vietnam Academy of Science and Technology \\ (VAST), 18-Hoang Quoc Viet, Cau Giay, 100000, Hanoi, Vietnam \\ ${ }^{2}$ Institute of Marine Biochemistry, VAST, 18-Hoang Quoc Viet, Cau Giay,100000, Hanoi, Vietnam \\ ${ }^{3}$ Electric Power University, 235 Hoang Quoc Viet, 100000, Hanoi, Vietnam \\ ${ }^{4}$ Faculty of Natural Science and Technology, Tan Trao University, Yen Son District, 300000, Tuyen Quang, Vietnam
}

Manuscript received on November 20, 2017; accepted for publication on March 4, 2018

\begin{abstract}
This paper evaluated the inhibitory effect of 3-O-[ $\beta$-D-glucopyranosyl-( $1 \rightarrow 4)-\beta$-D-glucuronopyranosyl] oleanolic acid 28-O- $\beta$-D-glucopyranosyl ester (PFS), a major saponin isolated from Polyscias fruticosa leaves, on $\alpha$-amylase and $\alpha$-glucosidase, and its potential for reducing the postprandial blood glucose level in mice. In enzyme inhibition assays, PFS strongly inhibited porcine pancreas $\alpha$-amylase and yeast $\alpha$-glucosidase. Using the Lineweaver-Burk equation, we found that PFS inhibited porcine pancreas $\alpha$-amylase in a mixed noncompetitive mode, and yeast $\alpha$-glucosidase via noncompetitive inhibition. In the sucrose tolerance test, PFS at $100 \mathrm{mg} / \mathrm{kg}$ body weight significantly decreased the postprandial blood glucose level in mice fed a high-sucrose diet. These findings suggest that $P$. fruticosa leaves and their major saponin PFS can be used to prevent and treat diabetes and its complications.
\end{abstract}

Key words: Polyscias fruticosa, Araliaceae, $\alpha$-amylase, $\alpha$-glucosidase, hypoglycemia.

\section{INTRODUCTION}

Diabetes mellitus is a metabolic disorder characterized by chronic hyperglycemia or increased blood glucose levels, which can damage the heart, blood vessels, eyes, kidneys, and nerves over time. Worldwide, the number of diabetics is expected to rise from 425 million to 629 million by 2045 (IDF 2017). High postprandial plasma glucose levels affect the complications of diabetes, primarily the macrovascular complications, more severely than an elevated fasting plasma glucose

Correspondence to: Nguyen Tien Dat

E-mail: ngtiend@imbc.vast.vn
(Haddadinezhad and Ghazaleh 2010). Therefore, it is important to control postprandial blood glucose levels to reduce the complications and mortality. $\alpha$-glucosidase and $\alpha$-amylase are two digestive enzymes that participate in glucose digestion. The inhibition of these enzymes would delay the degradation of starch and oligosaccharides, and thereby control postprandial hyperglycemia (Ghani 2015). $\alpha$-glucosidase and $\alpha$-amylase inhibitors currently in clinical use include acarbose, miglitol, and voglibose. However, the long-term use and high-dose administration of these drugs may cause adverse effects, such as diarrhea, abdominal pain, 
and flatulence (Lee et al. 2014). Herbal medicines with antihyperglycemic activity have been used as alternative treatments of type 2 diabetes, due to their reduced side effects and lower cost compared with synthetic hypoglycemic drugs (Rehman et al. 2015). Therefore, the search for safer, more effective hypoglycemic agents of natural origin has continued to be an important area of active research.

Polyscias fruticosa (L.) Harms (Araliaceae) is widely cultivated in Vietnam for medicinal and food purposes, production reaching up to several dozen tons/year. The plant has been used to treat ischemia and inflammation, and to increase blood flow to the brain. In addition, a root decoction and alcohol extract are used as tonics, and the leaves can be eaten as a salad (Vo 2012). Studies of the chemical composition and biological activities of $P$. fruticosa found that oleanolic acid-triterpene saponins and polyacetylenes were the main chemical constituents (Lutomski et al. 1992, Vo et al. 1998). Extracts of $P$. fruticosa leaves had antipyretic, anti-inflammatory, analgesic, and molluscicidal properties (Bernard et al. 1998, Asumeng Koffuor et al. 2015), as well as $\alpha$-glucosidase inhibitory and antidiabetic activities (Divakar and Bensita 1998, Mai et al. 2007). In our search for natural antidiabetic agents, we isolated an $\alpha$-glucosidase and $\alpha$-amylase inhibitor from a methanol extract of $P$. fruticosa leaves. The compound was identified as 3- $O$ - $[\beta$-D-glucopyranosyl- $(1 \rightarrow 4)-\beta$ D-glucuronopyranosyl] oleanolic acid 28-O- $\beta$-Dglucopyranosyl ester (PFS; Figure 1) (Hanh et al. 2016). This paper examines the $\alpha$-glucosidase and $\alpha$-amylase inhibitory activities, and hypoglycemic effects, of this compound.

\section{MATERIALS AND METHODS}

\section{COMPOUND AND ANIMALS}

The saponin 3- $O$-[ $\beta$-D-glucopyranosyl- $(1 \rightarrow 4)-\beta$ D-glucuronopyranosyl] oleanolic acid 28-O- $\beta$-D- glucopyranosyl ester (PFS) was isolated from the leaves of Polyscias fruticosa as indicated in our previous report (Hanh et al. 2016).

Healthy BALB/c mice, of either sex and weighing 24-28 g, were obtained from the Institute of Biotechnology, Vietnam Academy of Science and Technology. They were kept in clean cages maintained at $22-25^{\circ} \mathrm{C}$ and $50-70 \%$ humidity, and allowed free access to food and water. The use of the animals was approved by the Institutional Ethics Committee on Animal Protocols based on the Guide for the Care and Use of Laboratory Animals (National Institutes of Health, Bethesda, MD, USA).

\section{ASSAY FOR $\alpha$-GLUCOSIDASE INHIBITION}

The yeast $\alpha$-glucosidase (G0660; SigmaAldrich, St. Louis, MO, USA) enzyme inhibition assay involved digesting $p$-nitrophenyl- $\alpha-\mathrm{D}$ glucopyranoside (Hanh et al. 2016). The sample solution $(2 \mu \mathrm{L}$ dissolved in DMSO) was mixed with $0.5 \mathrm{U} / \mathrm{mL} \alpha$-glucosidase $(40 \mu \mathrm{L})$ in 120 $\mu \mathrm{L}$ of $0.1 \mathrm{M}$ phosphate buffer $(\mathrm{pH}$ 7.0). After a 5 -min pre-incubation, $5 \mathrm{mM} p$-nitrophenyl- $\alpha$-Dglucopyranoside $(40 \mu \mathrm{L})$ was added and the solution was incubated at $37^{\circ} \mathrm{C}$ for $30 \mathrm{~min}$. The absorbance of the released 4-nitrophenol was measured at 405 $\mathrm{nm}$ using a microplate reader (Molecular Devices, Sunnyvale, CA, USA). Acarbose was used as a positive control $\left(\mathrm{IC}_{50} 650.4 \mu \mathrm{g} / \mathrm{mL}\right)$.

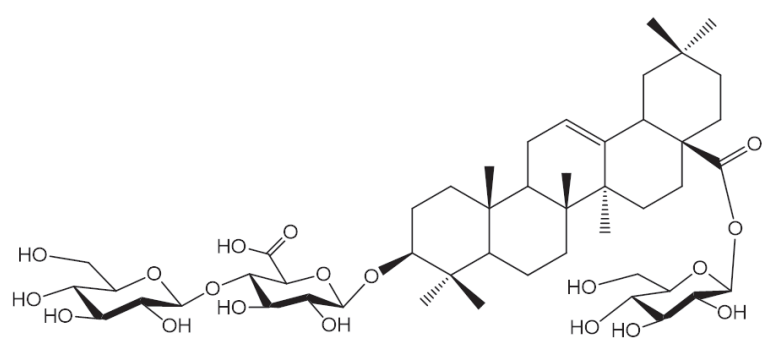

Figure 1 - The structure of saponin PFS. 


\section{ASSAY FOR $\alpha$-AMYLASE INHIBITION}

The porcine pancreas $\alpha$-amylase (A3176; SigmaAldrich) inhibitory activity was evaluated using 2-chloro-4-nitrophenyl- $\alpha$-D-maltotrioside (93834; Sigma-Aldrich) as the substrate (Hanh et al. 2016). The sample ( $2 \mu \mathrm{L}$ dissolved in DMSO $)$ and 0.5 unit/ $\mathrm{mL} \alpha$-amylase $(50 \mu \mathrm{L})$ were mixed in $100 \mu \mathrm{L}$ of 0.1 $\mathrm{M}$ phosphate buffer (pH 7.0). After a 5-min preincubation, substrate solution $(50 \mu \mathrm{L})$ was added and the solution was incubated at $37^{\circ} \mathrm{C}$ for $15 \mathrm{~min}$. The absorbance was measured at $405 \mathrm{~nm}$. Acarbose was used as a positive control $\left(\mathrm{IC}_{50} 57.6 \mu \mathrm{g} / \mathrm{mL}\right)$.

\section{KINETICS OF ENZYME INHIBITION}

The mode of inhibition of $\alpha$-amylase and $\alpha$-glucosidase by saponin PFS was determined using the Lineweaver-Burk equation. CNPG3 at concentrations of $1-5 \mathrm{mM}$, and $\mathrm{PNG}$ at concentrations of $0.3-1.5 \mathrm{mM}$, were used as substrates for $\alpha$-amylase and $\alpha$-glucosidase, respectively. The enzyme activity was determined in the absence or presence of different doses of test compound. The PFS concentrations used to examine the inhibitory kinetics of $\alpha$-amylase were 10 and $30 \mu \mathrm{g} / \mathrm{mL}$, whereas, 100 and $300 \mu \mathrm{g} / \mathrm{mL}$ were used for the $\alpha$-glucosidase inhibitory kinetics. The initial velocity was obtained according to the rate of increase in the absorbance of the reaction solution.

ORAL SUCROSE TOLERANCE TEST IN NORMAL MICE

Normal healthy mice were divided into three groups of six mice each. Group 1 served as the normal control group and received saline. Group 2 was treated with the antidiabetic drug acarbose at a dose of $5 \mathrm{mg} / \mathrm{kg}$ in saline. Group 3 was treated with saponin PFS at $100 \mathrm{mg} / \mathrm{kg}$ (dissolved in saline). The test samples, standard drug, and saline were given orally to mice fasted for $12 \mathrm{~h}, 30 \mathrm{~min}$ before the administration of sucrose $4 \mathrm{~g} / \mathrm{kg}$. Blood glucose levels were measured before and $0.5,1$, and $2 \mathrm{~h}$ after starch loading. A glucose tolerance curve was plotted and the trapezoidal rule was used to determine the area under the curve (AUC).

\section{STATISTICAL ANALYSIS}

Results are expressed as mean \pm standard deviation of the mean (SD). Data obtained from different groups were compared with each other by one-way analysis of variance (ANOVA). $p$ values less than 0.05 were considered to be statistically significant.

\section{RESULTS AND DISCUSSION}

\section{$\alpha$-AMYLASE AND $\alpha$-GLUCOSIDASE INHIBITION}

The inhibitory effects of the saponin PFS against porcine pancreas $\alpha$-amylase and yeast $\alpha$-glucosidase were evaluated in comparison with the antidiabetic acarbose. As shown in Figure 2, PFS dose-dependently inhibited both enzymes. The calculated $\mathrm{IC}_{50}$ was 27.1 and $440.5 \mu \mathrm{g} / \mathrm{mL}$ for $\alpha$-amylase and $\alpha$-glucosidase, respectively.

To clarify the inhibition mode of PFS, kinetic studies of the inhibitory effect of PFS on porcine pancreas $\alpha$-amylase and yeast $\alpha$-glucosidase were performed, using CNPG3 and PNG as the respective substrates. The initial velocity, $v$, of the enzyme was measured at various substrate concentrations, $[S]$, in the presence and absence of PFS. As indicated in the Lineweaver-Burk plot for $\alpha$-amylase inhibition (Figure 3a), PFS showed mixed noncompetitive inhibition kinetics as the lines intersected near the $x$-axis in the second quadrant. By contrast, the plots of $1 / v$ versus $1 /[S]$ gave a family of straight lines with different slopes that intersected on the $x$-axis, indicating that PFS exhibited noncompetitive inhibition of yeast $\alpha$-glucosidase (Fig. 3b).

HYPOGLYCEMIC EFFECT ON NORMAL MICE

Since the inhibition of $\alpha$-amylase and $\alpha$-glucosidase can lower postprandial glucose levels, the effect of saponin PFS on blood glucose levels was tested 

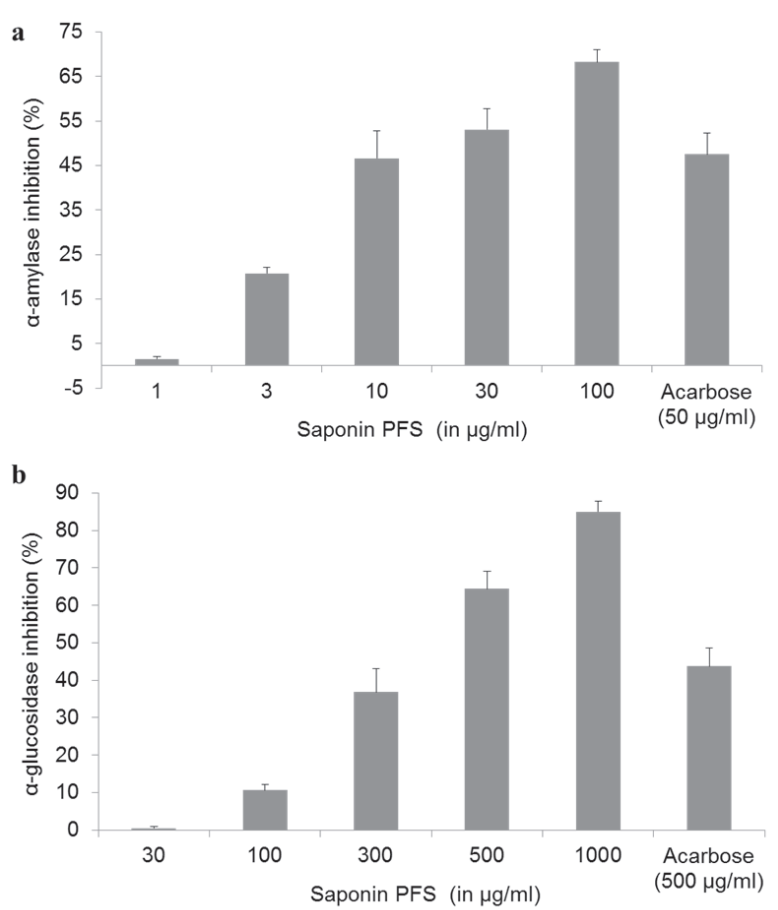

Figure 2 - Inhibitory effect of saponin PFS against $\alpha$-amylase (a) and $\alpha$-glucosidase (b). Acarbose was used as a reference at $50 \mu \mathrm{g} / \mathrm{ml}$ for $\alpha$-amylase and $500 \mu \mathrm{g} / \mathrm{ml}$ for $\alpha$-glucosidase assay. Bars represent standard deviations of triplicate measurements.

in vivo using a sucrose-loading test (Fig. 4a). A control group was loaded with saline only. The administration of sucrose ( $4 \mathrm{~g} / \mathrm{kg}$ body weight p.o.) to fasted mice resulted in a rapid increase in blood glucose concentrations from 100.8 to a maximum of $146.7 \mathrm{mg} / \mathrm{dL}$ after $30 \mathrm{~min}$. The normal blood glucose levels were restored after $120 \mathrm{~min}$. A significant $(p<0.05)$ suppressive effect on the blood glucose level was achieved with $100 \mathrm{mg} / \mathrm{kg}$ PFS in comparison with acarbose. The maximum hypoglycemic rates of the treated mice were $16.6 \%$ at $30 \mathrm{~min}$ and $27.9 \%$ at $60 \mathrm{~min}$, compared with the normal control group at each time point. To verify these differences, we measured the AUC of the glucose tolerance test (Fig. 4b). The AUCs of mice treated with PFS and acarbose were significantly $(p<0.05)$ lower than that of untreated mice. However, the saponin PFS at $100 \mathrm{mg} / \mathrm{kg}$ exerted a hypoglycemic effect that was weaker than that of acarbose at $5 \mathrm{mg} / \mathrm{kg}$.
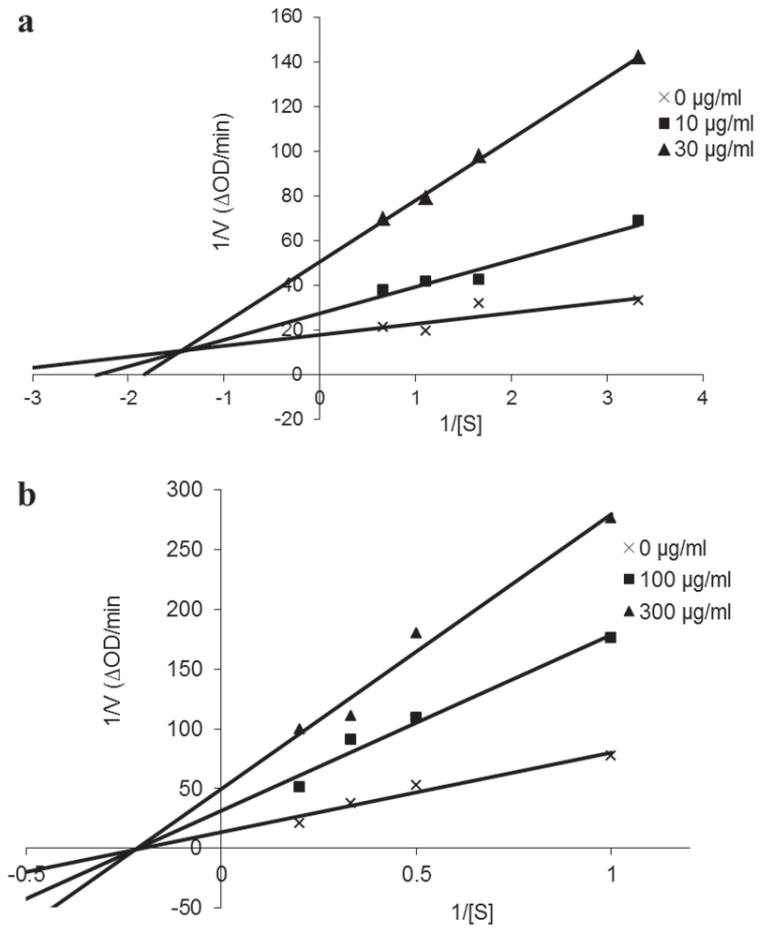

Figure 3 - Lineweaver-Burk plots of the reaction of porcine pancreas $\alpha$-amylase (a) and yeast $\alpha$-glucosidase (b) at different concentrations of substrate and saponin PFS.

Recent studies have revealed that a high postprandial plasma glucose level is more harmful than an elevated fasting blood glucose level: it not only causes serious complications but also increases mortality. Therefore, it is important to control postprandial blood glucose levels to reduce complications and mortality (Ketema and Kibret 2015). The inhibition of the digestive enzymes $\alpha$-amylase and $\alpha$-glucosidase is an effective strategy for lowering the level of postprandial hyperglycemia via the control of starch breakdown. Herbal remedies and alternative medicines are used worldwide, and herb-derived medications are still used extensively for the treatment of high blood pressure, diabetes, and other illnesses. Following the World Health Organization recommendations for diabetes mellitus (WHO 1980), the search for safer, more effective hypoglycemic pharmaceuticals from medicinal plants has continued to be an important area of active research. 

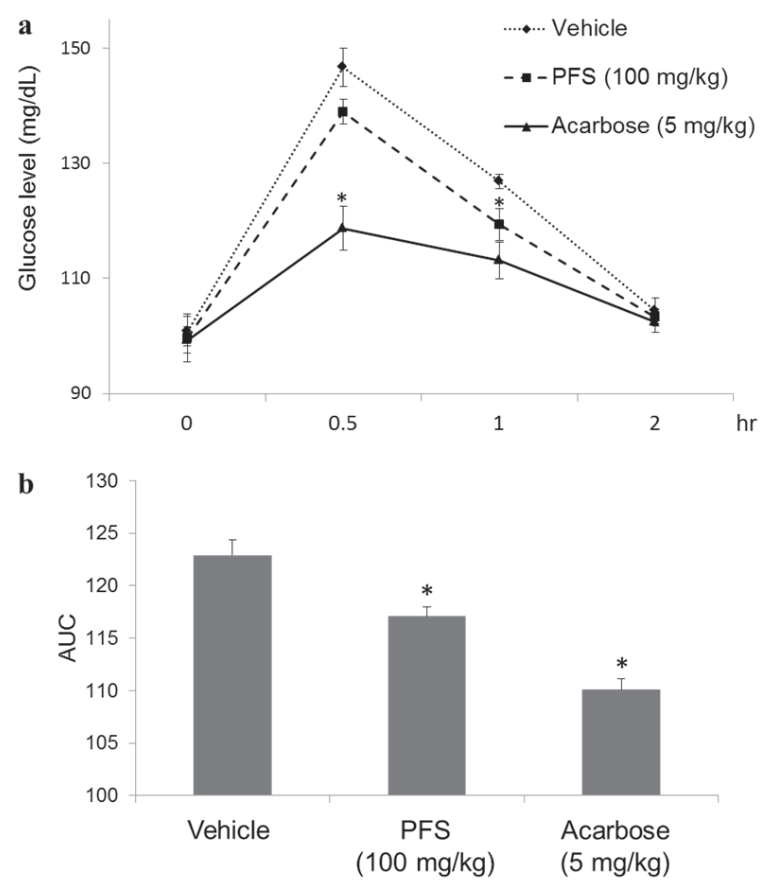

Figure 4 - Hypoglycemic effect of saponin PFS. a) Blood glucose levels after $4 \mathrm{~g} / \mathrm{kg}$ sucrose administration in normal mice. b) The incremental $\mathrm{AUC}_{0-120 \text { min }}$ in normal rats after sucrose administration. Bars represent mean $\pm \mathrm{SD}(\mathrm{n}=6)$, $* p<0.05$ compared with vehicle.

Polyscias fruticosa (L.) Harms leaf extracts strongly inhibited rat intestinal $\alpha$-glucosidase (Mai et al. 2007) and exhibited antidiabetic effects in a rat model (Divakar and Bensita 1998). Oleanolic acid saponins were found to be the main constituents of this plant (Vo et al. 1998). In the present study, 3-O-[ $\beta$-D-glucopyranosyl- $(1 \rightarrow 4)-\beta$ D-glucuronopyranosyl] oleanolic acid 28-O- $\beta$-Dglucopyranosyl ester (PFS) was isolated as a major compound, and strongly inhibited porcine pancreas $\alpha$-amylase and yeast $\alpha$-glucosidase. Synthesized saponin PFS also exhibited an inhibitory effect on $\alpha$-amylase and $\alpha$-glucosidase (Guo et al. 2015). Oleanolic acid saponins from plants in the Araliaceae are promising hypoglycemic agents (Yoshikawa et al. 1996, Narender et al. 2011). Our study showed that PFS prevented postprandial hyperglycemia in mice fed a high-sucrose diet. These results suggested that the observed hypoglycemic activity of PFS might be related to the inhibition of $\alpha$-amylase and $\alpha$-glucosidase. $P$. fruticosa is widely cultivated in Vietnam and used as both food and medicine, but has not been exploited for antidiabetic purposes. Our results suggest that P. fruticosa leaves and its major saponin PFS are promising antidiabetic medicines.

\section{CONCLUSION}

The major saponin 3-O-[ $\beta$-D-glucopyranosyl$(1 \rightarrow 4)$ - $\beta$-D-glucuronopyranosyl] oleanolic acid 28-O- $\beta$-D-glucopyranosyl ester (PFS) isolated from Polyscias fruticosa leaves strongly inhibited porcine pancreas $\alpha$-amylase and yeast $\alpha$-glucosidase. This compound also decreased the postprandial blood glucose level in a mouse model. The results support the inclusion of Polyscias fruticosa and PFS in traditional antidiabetic preparations and formulations.

\section{ACKNOWLEDGMENTS}

This work is supported by a grant from the National Foundation for Science and Technology Development (NAFOSTED 104.01-2015.29).

\section{REFERENCES}

ASUMENG KOFFUOR G, BOYE A, KYEI S, OFORIAMOAH J, AKOMANIN ASIAMAH E, BARKU A, ACHEAMPONG J, AMEGASHIE E AND KUMI AWUKU A. 2015. Anti-asthmatic property and possible mode of activity of an ethanol leaf extract of Polyscias fruticosa. Pharm Biol 8: 1-10.

BERNARD BM, PAKIANATHAN N AND DIVAKAR MC. 1998. On the antipyretic, anti-inflammatory, analgesic and molluscicidal properties of Polyscias fruticosa (L.) Harms. Anc Sci Life 17: 313-319.

DIVAKAR MC AND BENSITA MB. 1998. Screening of various leaf extracts of Polyscias fruticosa Harms for their antidiabetic activity. Indian J Nat Prod 14: 24-28.

GHANI U. 2015. Re-exploring promising $\alpha$-glucosidase inhibitors for potential development into oral anti-diabetic drugs: Finding needle in the haystack. Eur J Med Chem 103: 133-162.

GUO T, WU S, GUO S, BAI L, LIU Q AND BAI N. 2015. Synthesis and evaluation of a series of oleanolic acid 
saponins as $\alpha$-glucosidase and $\alpha$-amylase inhibitors. Arch Pharm 348(9): 615-628.

HADDADINEZHAD S AND GHAZALEH N. 2010. Relation of fasting and postprandial and plasma glucose with hemoglobinA1c in diabetics. Int J Diabetes Dev Ctries 30(1): 8-10.

HANH TTH, DANG NH AND DAT NT. 2016. $\alpha$-Amylase and $\alpha$-glucosidase inhibitory saponins from Polyscias fruticosa leaves. J Chem 2016: 2082946.

IDF. 2017. Diabetes Alats-8 Edition. http://www.diabetesatlas. org/ Accessed 20 Nov. 2017.

KETEMA EB AND KIBRET KT. 2015. Correlation of fasting and postprandial plasma glucose with $\mathrm{HbA} 1 \mathrm{c}$ in assessing glycemic control; systematic review and meta-analysis. Arch Public Health 73: 43.

LEE MY ET AL. 2014. Comparison of acarbose and voglibose in diabetes patients who are inadequately controlled with basal insulin treatment: randomized, parallel, open-label, active-controlled study. J Korean Med Sci 29(1): 90-97.

LUTOMSKI J, LUAN TC AND HOA TT. 1992. Polyacetylenes in the Araliaceae family. Part IV. The antibacterial and antifungal activities of two main polyacetylenes from Panax vietnamensis Ha et Grushv., and Polyscias fruticosa (L.) Harms. Herba Pol 38: 137-140.

MAI TT, THU NN, TIEN PG AND VAN CHUYEN N. 2007. Alpha-glucosidase inhibitory and antioxidant activities of Vietnamese edible plants and their relationships with polyphenol contents. J Nutr Sci Vitaminol 53: 267-276.

NARENDER T, KHALIQ T AND MADHUR G. 2011. Naturally occurring antihyperglycemic and antidyslipidemic agents. In: Tiwari VK and Mishra BB (Eds). Opportunity, challenge and scope of natural products in medicinal chemistry: Research Signpost, Trivandrum, p. 155-185.

REHMAN SU, CHOI MS, CHOE K AND YOO HH. 2015. Interactions between herbs and antidiabetics: an overview of the mechanisms, evidence, importance, and management. Arch Pharm Res 38(7): 1281-1298.

VODH, YAMAMURA S, OHTANI K, KASAI R, YAMASAKI K, NGUYEN TN AND HOANG MC. 1998. Oleanane saponins from Polyscias fruticosa. Phytochemistry 47: 451-457.

VO VC. 2012. Dictionary of Vietnamese Medicinal Plants, Vol. 1. Hanoi, Vietnam: Medical Publisher.

WHO. 1980. The WHO Expert Committee on Diabetes Mellitus. World Health Organ Tech Rep Ser 646: 1-80.

YOSHIKAWA M, MURAKAMI T, HARADA E, MURAKAMI N, YAMAHARA J AND MATSUDA H. 1996. Bioactive saponins and glycosides. VII. On the hypoglycemic principles from the root cortex of Aralia elata Seem.: structure related hypoglycemic activity of oleanolic acid oligoglycoside. Chem Pharm Bull 44(10): 1923-1927. 